\title{
Men found the early months of first time fatherhood challenging
}

\author{
Barclay L, Lupton D. The experiences of new fatherhood: a socio-cultural analysis.J Adv Nurs 1999 Apr;29:1013-20.
}

\section{Question}

What are men's experiences of first time fatherhood during the 6 months immediately after the birth of their infant?

\section{Design}

Longitudinal, naturalistic study.

\section{Setting}

Sydney, NSW, Australia.

\section{Participants}

15 men (approximate age range 24-37 y) who were experiencing fatherhood for the first time were recruited from preparenthood classes in a hospital. Men's occupations included factory supervisor, financial analyst, sales representative, nurses' aid, storeman, plumber, and psychologist.

\section{Methods}

Indepth, semistructured interviews were conducted for 1 hour on 4 occasions over approximately 6 months (just before the birth of the child until 5 or 6 mo after the birth). Interviews were done without the men's partners present. Data were sought on men's expectations, feelings, and experiences of fatherhood, and their contribution to decision making about child care. All interviews were audiotaped and fully transcribed. Discourse analysis was used to extract the men's beliefs and representations of their experiences.

\section{Main findings}

3 interrelated themes were identified. The first theme related to renegotiating paid employment and household work. Men wanted to be involved with their infant but were limited by factors such as their paid employment and partner's expectations. Men who lacked skill in household tasks and caring for their infant had to invest time and energy to develop these skills. Men differed in how they viewed parenting, household, and paid employment work. Families with men who had realistic expectations of and competence in household and infant work were advantaged.

The second theme related to expectations and symbolic meanings of fatherhood. Men expected to play the part of nurturer in "being there" for their infant; however, many found this to be unachievable immediately after the birth. Men expected their infants to be more socially responsive than they proved to be. Many men adjusted their expectations by anticipating that the desired emotional fulfilment would come later. Men found the infant's feeding to be symbolic of an intimate relationship. Although they understood the benefits of breast feeding, some men were disappointed because of their lack of involvement in it. Men who entered a care providing relationship soon after birth were quicker to achieve a bond with their infant.

The third theme related to the changing relationship with their partner. Men were surprised at the tension brought about in the relationship with their partners by the birth of the baby. Both partners struggled to feel good about their new roles. Partners had to find a balance between spending time with the baby and with each other. Those couples who had a framework of shared rules for behaviour and those who had no rules about parenting experienced the least tension in their relationship.

\section{Conclusion}

Men who were experiencing fatherhood for the first time emphasised the challenges they faced in renegotiating paid employment and doing household work, the redefinition of expectations of fatherhood based on their actual experiences, and the changing relationship with their partner after the birth of their infant.

Source of funding: The Australian Research Council.

For correspondence: Professor L Barclay, Family Health Research Unit, L2, J Laws House, St George Hospital, Kogarah, NSW 2217, Australia. Fax +61293503976.

\section{Commentary}

The study by Barclay and Lupton provides an interesting perspective on the concept of fatherhood in a "new man" contemporary western society. Most men in this qualitative study found fatherhood to be disappointing and frustrating in the early weeks after the birth of their child. They also expected to be more involved than they were.

A strength of this study is the extensive interview process, including 4 one hour interviews beginning before the birth of the baby. More information on the theoretical underpinnings of the study is required for an accurate critique. It would also be useful to have more information about discourse analysis. The study, however, examines an understudied and important topic and should be replicated with other cultures worldwide.
Despite the fact that the results are culturally specific to Australian men, they offer much in the way of evidence for nurses, midwives, and health visitors in their support of new parents. Although men thought they could nurture, invest emotional and physical energy in their children, and obtain increased emotional satisfaction in return, the unexpected immaturity of the infant and the men's lack of time to get to know the infant made these expectations unrealistic. Breast feeding excluded men from a close relationship with their child. Their impotence, as they struggled with new experiences, often resulted in anger or frustration at themselves and tense and strained relationships with their partners. The men felt inadequate, reluctant to share this with their partners, and guilty that they could not or did not help as much as needed.
Fatherhood has been studied far less than motherhood. The findings of this study show that first time fathering in contemporary western society requires men to be providers, household helpers, and nurturers. The demands of these roles and the tensions they produce challenge men's relationships with their partners and the meaning and place of work in their lives. These findings increase our understanding of the experiences of new fathers and emphasise the need to focus on the new father in our assessment, support, and education of new families.

Bridget Johnston, RGN, PGCE, BN (Hons) Lecturer in Palliative Care Srathcarron Hospice

Denny, UK 